\title{
CARTOGRAFANDO SABERES: POR ENTRE TRAÇOS RIZOMÁTICOS NO CURRÍCULO DE CIÊNCIAS NA EDUCAÇÃO DE JOVENS E ADULTOS
}

\author{
Edilena Maria Corrêa ${ }^{1}$
}

\section{Entre paisagens metodológicas: linhas introdutórias}

\begin{abstract}
Quando se advoga uma rebeldia aos currículos ditos ilegais, talvez valesse a pena nos inspirarmos no inconformismo de Nietzsche com métodos e programas. Há ainda no século 21, como na segunda metade do século 19, uma continuada necessidade de estarmos atentos à maneira como nos são impostos currículos dominadores em nossas salas de aula e rebeldemente nos inconformar com estes.
\end{abstract}

(CHASSOT, 2007, p. 156)

Problematizar as condições do conhecimento verdadeiro no currículo de ciências é importante, pois, permitem experimentações, criações que possibilitam outras maneiras de pensar tal currículo, que possam sair do gesso das verdades absolutas e é isso que nos mobiliza como pesquisadoras. As linhas traçadas nesse texto resultam de recortes de uma investigação realizada no decorrer dos anos de 2011 e 2012 em uma escola da rede pública do Município de Cametá, Estado do Pará, na Educação de Jovens e Adultos, por ocasião do curso de Mestrado em Educação em Ciências na Universidade Federal do Pará. O que nos interessou foi pensar a possibilidade de um currículo que tratasse os saberes dos estudantes como traços que expressam outras vozes, outros conhecimentos que emergem e que manifestam vontade de criação, de exercício com o pensamento, desdobrando atitudes inquiridoras a respeito do mundo que os cerca.

A pesquisa foi fazendo traçados, desdobramentos resultantes do que chamamos de aulasexperiências desenvolvidas na escola, com os estudantes da $3^{a}$ etapa EJA e um professor de ciências. O estudo partiu de uma inquietação/indagação, se um currículo que valorize os saberes dos estudantes, que emergem no entre do currículo oficial, que considere o múltiplo, a diferença, poderia fomentar novos modos de existência e experiências criativas com a Educação de Jovens e Adultos no que diz respeito ao ensino de ciências. Dessa maneira, elegeu-se como questões norteadoras: o que podem esses saberes? Que modos, que experiências poderiam ser pensadas no espaço escolar da EJA/Cametá no ensino fundamental que pudessem possibilitar um currículo acontecimento? É possível pensar uma imagem de currículo de Ciências da EJA, que esteja para além do mero posto e seja a favor da diferença?

Pensamos que um currículo que não esteja preso pela estrutura, pela ordem, pode mobilizar uma forma de ensino e aprendizagem pela diferença, pela multiplicidade e com isso favorecer a transversalidade e permitir outras vias para o ensino de ciências, ligadas pelo alargamento cultural e diferença.

O estudo tomou como objetivos investigar que possibilidades e efeitos esses sabres trazem para o currículo de ciências da EJA, em que aspectos uma imagem de currículo que valorize os saberes diversos poderia contribuir para um ensino de ciências não dogmático e, pensar possibilidades de um currículo de ciências com a EJA que esteja para além do prescrito no currículo oficial, para além da identidade. A pesquisa foi configurada por meio de um

\footnotetext{
1 Professora da Universidade Federal do Pará-Campus do Tocantins-Cametá. E-mail: edilenacorreia@ yahoo.com.br
} 
percurso cartográfico que priorizou movimentos e processos e possibilitou pensar um currículo de ciências por linhas de fuga, por traços, vazões às suas intensidades.

Embasadas na obra de Deleuze e Guatarri (1995), que trazem o conceito de cartografia como um princípio do rizoma, ressaltamos que a pesquisa é então descrita como linhas em constantes movimentos e rearranjos, compreendendo um plano de composição de elementos heterogêneos, em que a prática da pesquisa não é definida de antemão, mas se constitui no caminhar, o plano aqui pensado é um currículo de ciências com a EJA. Nesse processo os planos foram sendo redefinidos a cada momento, sendo movimentados, criados, experimentados, mobilizados, percebendo-se as múltiplas entradas e saídas, pois, a cartografia é compreendida também como um rizoma.

É assim que Deleuze e Guattari designam sua Introdução: Rizoma. A cartografia surge como um princípio do rizoma que atesta, no pensamento, sua força performática, sua pragmática: princípio "inteiramente voltado para uma experimentação ancorada no real" (Deleuze e Guattari, 1995, p. 21). Nesse mapa, justamente porque nele nada se decalca, não há um único sentido para a sua experimentação nem uma mesma entrada. [...]. A realidade cartografada se apresenta como mapa móvel, de tal maneira que tudo aquilo que tem aparência de "o mesmo" não passa de um concentrado de significação, de saber e de poder, que pode por vezes ter a pretensão ilegítima de ser centro de organização do rizoma. Entretanto, o rizoma não tem centro (PASSOS, KATRUP e ESCOSSIA, 2009, p. 10).

Posto essas linhas introdutórias, destacamos alguns desdobramentos resultantes das aulasexperiências desenvolvidas em uma escola pública do município de Cametá-Pa, com os estudantes da $3^{\mathrm{a}}$ etapa EJA, que fizeram ver e pensar um currículo como acontecimento, aquele que ocorre ali no cotidiano da sala de aula, na dobra do singular, das singularidades emergentes.

\section{Do acontecimento e currículo de ciências}

Na obra Lógica do sentido, Deleuze fala do acontecimento, enfatizando que,

O acontecimento não é o que acontece (acidente), ele é no que acontece puro expresso que nos dá sinal e nos espera. Não há acontecimentos privados e outros coletivos; como não há individual e universal, particularidades e generalidades. Tudo é singular. (...) é por isso coletivo e privado ao mesmo tempo, particular e geral, nem individual nem universal (DELEUZE, 2009, p. 155).

Nesse sentido, o autor indica que o acontecimento puro é impessoal, não adere, é movimento. $\mathrm{O}$ acontecimento se constitui entre linhas, e é nessa perspectiva que nos propusemos pensar um currículo de ciências, por multiplicidades, possibilidades, por múltiplos saberes que o atravessam, que não se deixam fixar pela ordem prática de uma objetividade neutra.

O acontecimento é aquilo que singulariza, não há valor intrínseco, mas tão somente atributivo. $\mathrm{Na}$ educação em ciências a ordem epistemológica do saber científico deseja percorrer a generalidade e não a singularidade, pois, trabalha por padrões, por métodos, objetividades, regularidades. $\mathrm{O}$ acontecimento insiste em afirmar a diferença, a singularidade. Por mais que uma aula comporte a repetição do professor que entra na sala, inicia sua aula, introduz um conteúdo, realiza experimentos, etc, tal situação histórica pode acontecer todos os dias da semana, mas nunca vai ser igual. 
Para Deleuze há uma temporalidade no acontecimento, esses tempos se misturam. O tempo do cronos (misturas dos corpos, cronologia do tempo, forma cíclica, um passado, presente e futuro, prescinde uma ordem das causas, sucessão de instantes), O tempo do aion (está ligado a noção de incorporal, o presente sempre em fuga, em passagem, em fluxo, sua forma, a linha reta ilimitada). O problema será como compor a linha cíclica a reta ilimitada. Por esse motivo, o acontecimento passará por ambos os registros de modo que ocorre a encarnação dos corpos e ocorre estados de coisas, a passagem, o incorporal, aquilo que não adere, não fixa sempre qualquer coisa que acabou de passar ou que vai passar, contudo, isso se ocorre simultaneamente, jamais qualquer coisa que se passa (DELEUZE, 1969, p. 78).

O pensamento Deleuziano ignora os grandes acontecimentos históricos, ele quer saber das multiplicidades, daquilo que ocorre nas singularidades, ele se preocupa com a qualidade das forças que podem emergir de um acontecimento, os efeitos, nunca a necessidade de causas. Quando tratam essas questões na ordem da ciência, Deleuze e Guattari, no Tratado de Monadologia, fazem referência a duas ciências, uma que ele chama de maior e outra de menor.

A ciência maior tem uma temporalidade objetiva, estrutural e fixável. A ciência menor faz passagem, é uma ciência das variações, do estrato liso, ela é efetivamente, para os autores, um saber que percorre o acontecimento. Contudo, para Deleuze é possível asseverar uma correlação entre ambas, desde que se possam intuir questões da ciência maior à estrutura de variações da ciência menor. Pensamos que agora seria possível entender o que chamamos de misturas de saberes no currículo de ciências, pois, não há regras que digam que uma mistura e não outra pode ser considerada má, toda mistura vale o que valem os corpos que se penetram e as partes que coexistem (DELEUZE, 2009, p. 134). Nesse sentido buscamos pensar um currículo de ciências como acontecimento, em que perpassa por multiplicidades, por movimentos que não visualizam uma única direção, um único sentido, mas que estão sempre em trânsito pelos diversos campos de saberes, não seleciona, mas mistura, conecta, transversaliza.

\section{Aulas experiências entre misturas de saberes: acontecimentos}

Em uma das aulas de ciências em que o professor falava sobre a poluição da água, os estudantes expressaram seus saberes sobre a pesca local. Essa manifestação de saberes mobilizou-nos para pensarmos uma aula sobre a água e sua relação com o pescado em CametáPa. A partir da elaboração de um texto que trazia informações sobre as diferentes formas de poluição e também de contaminação da água, sobre a relação desses fatores com produção e/ou diminuição do pescado e a respeito dos nutrientes presentes no mapará ${ }^{2}$ que é bastante consumido pela população cametaense, mas que pouco se conhecia sobre seu valor nutricional. As aulas sobre a água e a relação com o pescado no município de Cametá não seguia o que estava prescrito no currículo escolar, todavia pensamos que são esses fluxos no currículo que fazem dele um acontecimento. A imagem abaixo retrata a pesca artesanal do mapará que ocorre em Cametá a mais de trezentos anos.

\footnotetext{
2 Peixe de couro, de água doce, da família dos Pimelodídeos, Siluróide (Hipophtolmus ssp), que vive, principalmente no Rio Tocantins, micro-região de Cametá.
} 


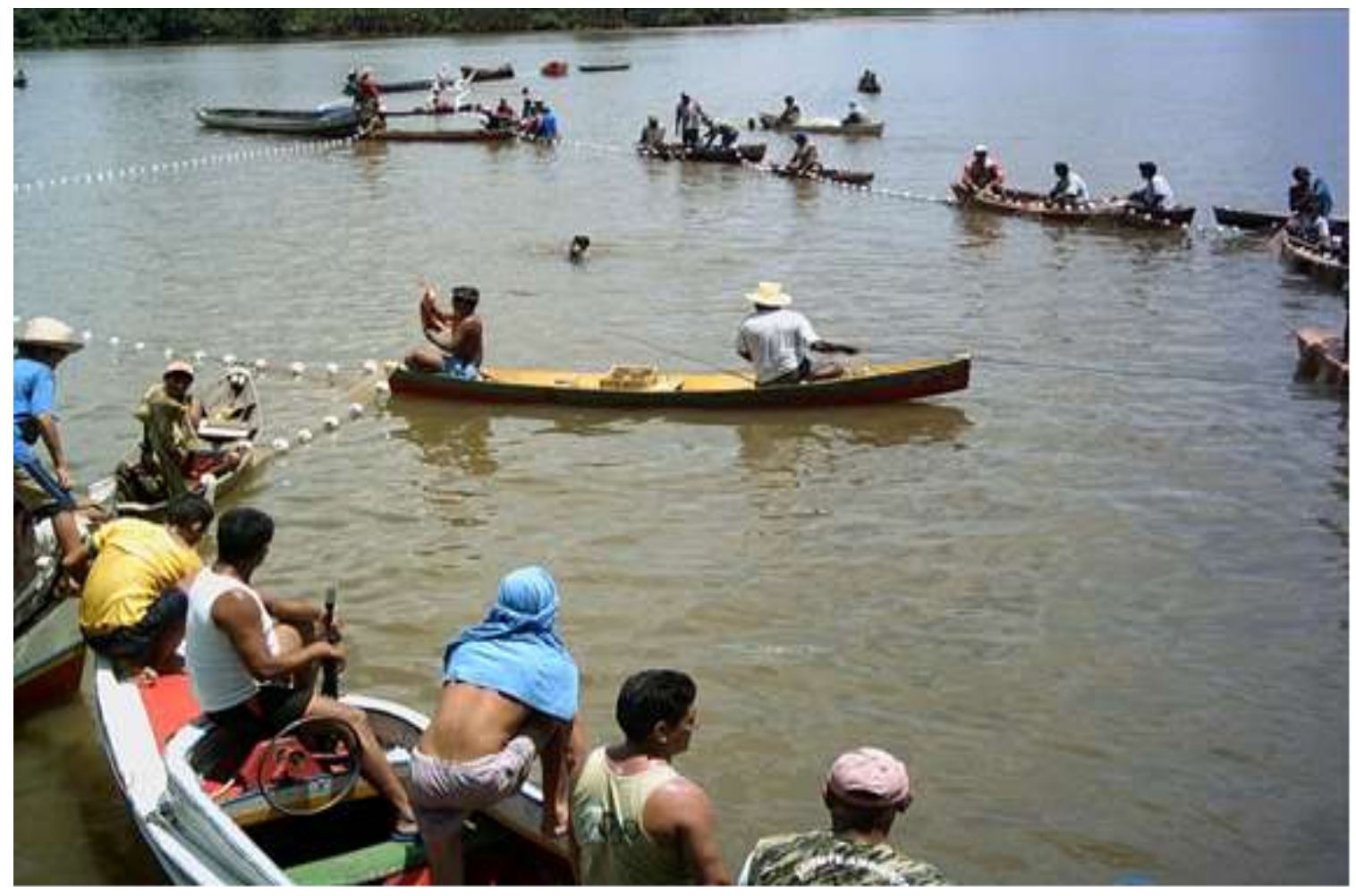

Fonte: Colônia dos Pescadores Z-16 de Cametá

A pesca do mapará envolve personagens como: camboeiros, taleiro, mergulhadores e mopongas ${ }^{3}$, cada um com uma função específica no processo de captura do mapará. No decorrer da aula, Maria, estudante da turma, a partir de seus conhecimentos, explicou a função e importância de cada personagem no processo da pesca ${ }^{4}$. A estudante expôs seus saberes sobre o tema daquela aula, tornando a aula mais viva, capaz de romper e conectar linhas curriculares.

Naquela aula em que o saber de Maria emergiu sem que isso estivesse naquele planejamento, vimos que a sala de aula é um espaço de experiências, de acontecimentos.

\footnotetext{
${ }^{3}$ Personagens que atuam na pesca artesanal do mapará no município de Cametá. Os camboeiros, são os pescadores que organizam a pesca, também chamada de cambôa. O taleiro, com a utilização de uma tala, localiza o cardume. Os mergulhadores mergulham para prender a rede no fundo do rio, e os mopongas são as pessoas que entram na água para fazer barulho com as mãos para acuar o mapará na rede.

${ }^{4}$ No começo de março, quando a pesca está liberada, os pescadores se reúnem para fazer o borqueio ou cambôa, como é chamada a pesca. Cada um faz uma coisa ali dentro. Tem os camboeiros, que são os que organizam a pesca. O taleiro, que é quem procura onde está o cardume para ser capturado, os mergulhadores que são quem entram na água para amarrar a rede, prender no fundo do rio, e os mopongas, que são os homens que fazem o barulho na água com as mãos para fazer o peixe ficar acuado dentro da rede. O borqueio acontece da seguinte forma: Quando os camboeiros querem fazer o borqueio, chamam o taleiro, este com seu instrumento (uma tala de marajá com uma linha de pesca presa à ponta e um peso amarrado no fim da linha) vai localizar onde estáo cardume, a quantidade e o tamanho do peixe, que deve ser se é o tamanho permitido pela lei.O taleiro com seu instrumento, consegue identificar se o cardume é de mapará ou de outro peixe, e ainda para que lugar o cardume está se dirigindo. Isso indica onde deve ser estendida a rede. Feito isso, os mergulhadores começam a trabalhar, estendem a rede e mergulham para prendê-la. É então a vez dos mopongas, que entram na água para fazer barulho batendo a água com as mãos. Quando tudo isso é feito, então vai se retirar a rede que vai estar cheia de mapará (Trecho retirado do diário de campo, sobre a fala de Maria na aula do dia 04/05/2012).
} 
De realidades que se tecem por linhas dos conhecimentos, da vida desses estudantes. Amorim (2004) ressalta que as relações entre currículo e vida seriam pensadas como uma metamorfose de multiplicidades, que se conectam e rompem no traçado de linhas nãolineares por entre os numerosos campos de saberes, que necessitaria ser reconhecida, percebida, olhada, tirando do foco as linhas da segmentaridade. São esses saberes dos estudantes que precisam ser olhados, pois, mesmo com um currículo que busca controlar, organizar, direcionar, homogeneizar, ainda há escapes, vazamentos, que não devem ser ignorados pela escola, pelo professor.

Paraíso (2010 p. 58) aborda que um currículo é um território de multiplicidades, de disseminação de saberes diversos, de encontros, de composições "caóticas", de disseminações "perigosas", de contágios "incontroláveis", de acontecimentos "insuspeitados". Ele é rizomático porque é território de proliferação de sentidos e multiplicações de significados, e mesmo com todas as tentativas de controle feitas pelos poderes, que tentam demarcar áreas, manter a ordem, a organização, há vazamentos, foge ao controle. "Por que não pensar o currículo por meio de suas bifurcações? Por que não experimentar no currículo o jogo da diferença? Por que não pensar o currículo por meio de seus vazamentos? Por que não priorizar a diferença em vez da identidade?"

Pensar um currículo de ciências com a EJA por vias dos vazamentos é pensar um currículo que acontece, compreendendo acontecimento como aquilo que foge da previsão, como os saberes dos estudantes expressos nas aulas, fugiram ao previsto no planejamento. $\mathrm{O}$ acontecimento é sempre aquilo que foge ao planejado, ao previsto, no caso em questão, escapou ao previsto no currículo de ciências daquela turma de EJA.

O currículo, portanto não tomado como algo pronto, mas como uma constante construção, aberto a possibilidades, experimentações, por suas linhas virtuais, por devires, movimentos infinitos. Pensar um currículo de ciências como acontecimento, como mapa, permitindo entradas múltiplas e diferenciadas, pode possibilitar potencialidades no ensino e na aprendizagem em ciências dos estudantes da EJA do município de Cametá. "É preciso possibilitar o acontecimento em um currículo! Deixar vazar! Fazer matilhas! Contagiar! Possibilitar outro currículo; um currículo que pense com a diferença para ver, sentir e viver a vida em sua proliferação. Experimentar em um currículo" (PARAÍSO, 2010 p. 602).

\section{Currículo entre linhas menores}

Na obra Kafka por uma literatura menor, Deleuze e Guatrii, trazem três características importantes de uma literatura menor. A primeira, é de que a língua aí é modificada por um forte coeficiente de desterritorialização; a segunda, a de que na literatura menor tudo é político e, a terceira, a de que na literatura menor tudo adquire um valor coletivo. Schollammer, em Práticas de uma língua menor: reflexões sobre um tema de Deleuze e Guatarri, enfatiza que, no caso histórico de Kafka, trata-se de um escritor que escreve em alemão como parte de uma minoria judia em Praga e, portanto, é desterritorializado triplamente. Não escreve em tcheco, a língua de sua prática, não escreve em iíndiche, a língua de sua comunidade, mas escreve um alemão deficitário, deslocado da língua maior. Essa escrita revela intensidades, linhas de fuga e metamorfoses principalmente no devir animal.

Assim pensamos que os saberes dos estudantes da EJA se constituem como um saber menor dentro do saber maior. Um "currículo menor" aí estabelece-se como linha de fuga ao "currículo maior", que se expressa através do currículo oficial, compreendendo o sujeito como universal e com isso, universalizando o conhecimento. Gallo, (2003) traz uma importante contribuição quando a partir da teoria de Deleuze enfatiza a respeito de uma educação menor. Segundo ao autor, uma 
educação menor é um ato de revolta contra os fluxos instituídos e de resistência à políticas impostas. Seria a sala de aula um espaço a partir do qual traçamos nossas estratégias, estabelecemos nossa militância. Nesse sentido, uma educação menor é um ato de singularização e de militância.

Falar de um currículo em linhas menores lembra-nos situações vivenciadas no decorrer das aulas experienciadas durante a pesquisa. Situações em que os saberes dos estudantes emergiam e se entrelaçavam com os conhecimentos advindos do currículo oficial de ciências. Falas dos estudantes que naquele momento davam sentido aos conteúdos de ciências. Saberes que davam sabores ao ensino e à aprendizagem. Em uma das aulas, o professor falava sobre o processo de fotossíntese, quando Júlia, estudante, ressaltou.

Tenho uma planta em casa que quase não pegava sol. Observei que pouco crescia. As folhas estavam feias, parecia que ia morrer. Um dia passei em uma área de campo e vi que uma planta igual a minha que ficava direto tomando sol estava linda. A partir daquele daí passei a colocar minha planta para tomar mais sol. Ela cresceu, se desenvolveu. Sabia que o sol fazia bem ás plantas, só não sabia porque. Agora, depois dessa aula, que diz que o sol alimenta as plantas, já sei porque as plantas crescem mais quando tomam sol (Diário de campo, 10/05/2012).

O saber de Júlia sobre a importância do sol para o desenvolvimento dos vegetais se constitui como um "saber menor" que se configura como potência para o ensino de ciências. Menor não no sentido de ser menos importante. Deleuze, sobre literatura menor, ressalta que uma literatura menor não é uma língua menor, mas antes, a que uma minoria faz em uma língua menor. O saber de Júlia sobre a importância do sol para o desenvolvimento dos vegetais, é um saber menor que ela possui em relação ao saber maior, aquele presente no currículo. Então, não é negar a importância dos conhecimentos escolares, mas dar importância também a outros saberes. Tomamos aqui o currículo oficial como maior para fazer referência aos saberes dos estudantes que emergem nas entrelinhas desse currículo. Esses saberes, que quebram esse ciurrículo maior, constituem o que chamamos nesse texto de "currículo menor". Que resiste, que subverte o currículo maior.

Pensamos que um currículo de ciências por linhas menores, tomando o saber dos estudantes como potência que possibilite movimentos, bifurcações, permitindo o entrelaçamento, a conexão entre os saberes por diversos pontos, um currículo que permita diversas entradas e saídas, pode trazer ao invés do uno, o múltiplo, através da possibilidade de encontros, de composições. Contudo, segundo Gallo (2003) não interessa à educação menor criar modelos, propor caminhos, impor soluções. Não se trata de buscar a complexidade de uma suposta unidade, o importante é fazer rizoma.

Um currículo menor assim pensando como aquele que acontece na sala de aula, no cotidiano das escolas, nos encontros de professores e estudantes, um currículo menor de ciências poderia se constituir, acompanhando a potência criadora dos saberes, pois um currículo sempre está aberto a novos acréscimos, a criações.

\section{Currículo é lugar de multiplicidades, de possibilidades, de fazer, de experimentar rizoma}

Escrevemos o Anti-Édipo a dois. Como cada um de nós era vários, já era muita gente. Utilizamos tudo o que nos aproximava, o mais próximo e o mais distante. (...) Não somos mais os mesmos. Cada um reconhecerá os seus. Fomos ajudados, aspirados, multiplicados (DELEUZE-GUATTARI, 1995, p. 17). 
O trecho é um comentário de Deleuze e Guatarri, sobre a escrita do Mil Platôs. Assim, falamos do processo de experimentar um currículo com um professor e estudantes da EJA do município de Cametá-Pa. Experimentamos um currículo atravessado por multiplicidades de saberes, experiências, ideias, desejos, valores. Cada um de nós também era vários.

Utilizamos as teorias de Deleuze e Guatarri como ferramentas para que pudéssemos pensar e experimentar um currículo por outra perspectiva com o professor e os estudantes da EJA. Elas inspiraram-nos por suas possibilidades de ver os conhecimentos por indissociabilidade, multiplicidade, ordem, mas a ordem da aliança entre os saberes.

A partir do conceito rizoma abordado por Deleuze e Guatarri (1995), que traz outra maneira de pensar como forma de combater ao privilégio secular da árvore, dialogamos sobre o currículo de ciências numa perspectiva rizomática, transversal, que não tem um começo nem um fim, mas sempre um meio que permite pensar como forma de resistência ao currículo arborescente fixado sempre num solo de verdade.

$\mathrm{Na}$ tentativa de possibilitar rizomas, permitir que no currículo de ciências os saberes conectem pontos quaisquer, sem posições, sem estruturas, pelo intermezzo pensamos que um currículo de ciências na perspectiva rizomática favorece a conexão de diversos saberes que se movem, se atravessam, que podem ser vistos como potências para o processo de ensino e aprendizagem em ciências dos estudantes da EJA do município de Cametá. Foi o que fizemos nas aulas de ciências, quando o professor e eu retomamos os saberes sobre a pesca, abordados por Maria na primeira aula, e exibimos um vídeo sobre a pesca em Cametá.

Os estudantes assistiam atentos, faziam anotações. Em seguida, falaram a respeito da importância do "período de defeso", assim chamado pelos estudantes como o período em que os peixes se reproduzem. Os estudantes destacaram ainda sobre o "acordo de pesca", uma política realizada pela colônia de pescadores do município de Cametá que incentiva as localidades a não capturar peixes durante o período de reprodução. Destacamos a importância desse "acordo" para a garantia do mapará às gerações futuras. E, foi assim que falamos de sustentabilidade, de como usufruir dos recursos da natureza, mas preocupando-se com as futuras gerações.

Ressaltamos ainda que nessa mesma aula também falamos sobre nicho ecológico e habitat. Esses conteúdos não estavam no planejamento da aula, mas como diz Deleuze, tudo escapa, tudo flui por linhas moleculares. Os estudantes expuseram seus conhecimentos a respeito dos saberes do taleiro em relação a localização do cardume do mapará utilizando apenas seu instrumento artesanal (uma tala) e seus conhecimentos. Falamos sobre nicho ecológico, relacionando o conhecimento do pescador tem sobre o peixe (habitat, alimentação, movimento, período de reprodução), seus hábitos, que fazem com que o taleiro localize o cardume do mapará sempre com precisão. Voltamos a ressaltar que esses conteúdos não tinham sido pensados para serem trabalhados naquela aula, mas na educação é preciso abrir-se ao inesperado, romper direções, permitir fluxos, rizomas.

Nessa dimensão o currículo não seria tomado pela lógica binária, do saber popular e saber escolar, ou pela hierarquia dos saberes, mas pela conexão destes, pois, um rizoma não é um múltiplo que deriva do Uno, é feito de dimensões e não de unidades. Ele não tem começo nem fim, mas sempre um meio pelo qual ele cresce e transborda (DELEUZE E GUATARRI, 1995).

Para entendermos o rizoma como forma de expressão da multiplicidade, Deleuze e Guatarri (1995), trazem seis características aproximativas do rizoma quais sejam: Conexão $e$ heterogeneidade: porque qualquer ponto de um rizoma pode ser conectado a qualquer outro e deve sê-lo, contudo, não ficando homogêneo por estarem conectados; multiplicidade: porque é somente quando o múltiplo é tratado como multiplicidade que não tem mais nenhuma relação com a unidade de sujeito ou objeto, tendo somente determinações, grandezas, dimensões; ruptura assignificante: porque um rizoma pode ser rompido, quebrado, e retomado em linhas; Cartografia e decalcomania: 
porque é um mapa aberto, produzido, desmontável que possibilita múltiplas entradas e saídas, não podendo ser justificado por nenhum modelo estrutural, por princípios de decalque.

As aulas- experiências realizadas com os estudantes e o professor de ciências permitiramnos pensar que o currículo de ciências traçado por linhas fixas, de ordem hierárquica e homogênea, que se constitui como eixo do processo de ensino e aprendizagem em ciências, acaba por delimitar, demarcar fronteiras, com isso delimita a presença dos saberes. Determina, julga que saber é mais importante. Esse limite implica negligenciar a diferença, não valorizar saberes que os estudantes trazem e que fluem como potência no processo educacional.

O que Maria falou sobre a pesca, não estava ali no currículo de ciências da EJA, aquele que prescreve os conteúdos de ciências a serem trabalhados pelos professores. Berticelli ( 2005 $\mathrm{p}, 165)$ ressalta que "a prescritividade continua presente em toda a ideia de currículo e em todas as práticas curriculares. Contudo, não se sustenta mais manter um critério curricular universal e um currículo fechado em uma prescritividade única. [...] currículo diz respeito a saberes, conteúdos, competências, símbolos, valores".

Os saberes dos estudantes da EJA nos fizeram pensar nas forças presentes no currículo, forças de estabilização, quando se pensa no currículo oficial e, desestabilização, quando pelas margens emergem outros saberes que estão além do currículo institucionalizado. Mostrou-nos que esses conhecimentos abrem outras possibilidades para pensar um currículo de ciências não para, mas com os estudantes da EJA do município de Cametá. Pensar com, pensar junto e experimentar junto, não escrever sobre, mas escrever junto. Decidir, em cada caso, de acordo com as linhas de afecto e de velocidade que constituem as coordenadas daquele agenciamento, daquele encontro de corpos, daquela composição (TADEU, 2004). Tomar um currículo a partir dessa perspectiva, significa pensar um currículo de ciências e o conhecimento não como modelo, que paralisa, que está preocupado em captar o conhecimento verdadeiro, mas toma-lo como criação, por suas forças que permitem movimentar, experienciar, promover encontros.

A partir dos saberes dos estudantes experimentamos, além de aulas, um currículo, escrevendo nele, movimentando-nos no ritmo com ele, como ressalta Tadeu (2004). Isso permitiu abertura aos atravessamentos, aos fluxos no currículo de ciências, que é movimento, multiplicidade, rizoma, pois um currículo também se faz pelo meio, como um rizoma que não começa nem conclui, mas que se encontra sempre no meio, entre as coisas, e, o meio não é uma média, mas o lugar onde as coisas adquirem velocidade" (DELEUZE e GUATTARI, 1995).

Os saberes de Maria e dos demais estudantes da EJA permitiram-nos pensar e experimentar um currículo por linhas rizomáticas expressando as multiplicidades de saberes sem ter que se focar na unidade. Experimentamos um currículo e não $o$ currículo, pois, a indefinição permite o movimento, a expressão do múltiplo, o atravessamento dos saberes no currículo de ciências da EJA.

A manifestação dos saberes no entre do currículo ali na sala de aula, levou-nos a pensar um currículo na perspectiva rizomática, entendendo o rizoma como algo que agencia e que, portanto não deve ser pensado como estrutura. Na sala de aula, experimentamos um currículo que não foi o "puramente" criado e orientado por especialistas, mas construído, negociado, atualizado ali na escola, na sala de aula pelos envolvidos no processo de ensino e aprendizagem.

Esse currículo não se constitui modelo para os estudantes da EJA do município de Cametá ou de qualquer outro lugar, mas traz traços para pensar um currículo de ciências numa perspectiva flexível, vivo, de uma comunidade que tem em seus saberes, potencialidades, que permitem pensar de maneira conectável, reversível, se constituindo a todo instante, de formas outras, escapando dos engessamentos por suas linhas de fuga.

Quando Deleuze e Guatarri (1995) trazem alguns princípios do rizoma, reafirmam a não fixidez, o descentramento, a multiplicidade. Através do princípio da conexão, em que um ponto 
pode ser ligado a outro, pensamos e experimentamos um currículo de ciências que transversalizasse os saberes, independente de um se constituir nas experiências, no trabalho, nas atividades cotidianas dos estudantes, e o outro, presente no currículo da instituição escolar, mas sem nenhuma conexão com tais saberes.

Quando falam do princípio da heterogeneidade, Deleuze e Guatarri referem-se às diversas linhas do rizoma, além das linguísticas, as biológicas, as políticas, as culturais, as materiais e as econômicas, no entanto, uma não se sobrepõe à outra mas se conectam de forma heterogênea em um mesmo plano. Assim pensamos e experimentamos um currículo atravessado pelos diversos saberes resultantes de múltiplas vivências. Não pela superioridade de um em relação ao outro, mas por agenciamentos que fazem conectar tais conhecimentos em um mesmo plano, o plano do currículo. Pelo princípio da multiplicidade abordado pelos autores, não faz mais sentido entender o currículo como unidade, mas como multiplicidade expressa através do rizoma.

Ver os saberes no currículo de ciências da EJA numa perspectiva múltipla possibilita escapar do esquema binário permitindo lugar às forças que ligam os saberes. Para Deleuze e Guatarri, a perspectiva rizomática, vai na contramão da unidade, a favor das multiplicidades, estas que não se caracterizam como pontos fixos, mas como linhas de um plano que se entrelaçam, que estão sempre em expansão, se movimento.

Como quarto princípio, os autores enfatizam o de ruptura assignificante, em que um rizoma pode ser quebrado em um lugar qualquer. Assim também o currículo de ciências da EJA pode ser fissurado. Porém, faz-se uma ruptura, traça-se uma linha de fuga, mas corre-se sempre o risco de reencontrar nela organizações que reestratificam o conjunto (DELEUZE E GUATARRI, 1995), pois num currículo, assim como no rizoma, além das fissuras, das linhas de fuga, se fazem presente árvores e raízes. Importa aqui é pensar que os saberes não se hierarquizam, não se sobrepõem, como também não se imitam. O que se pensa nessa perspectiva é um devir, movimentos de linhas de saberes, que se atravessam e produzem sempre novos agenciamentos.

Como quinto e o sexto princípios do rizoma, os autores trazem a cartografia e a decalcomania, ressaltando que um rizoma não pode ser justificado por nenhum modelo estrutural, assim sendo, se configura como um mapa que está sempre em alteração. Ele é aberto, conectável em todas as suas dimensões, desmontável, reversível, suscetível de receber modificações constantemente. Ao contrário do decalque que volta sempre ao mesmo, o mapa tem múltiplas entradas (DELEUZE E GUATARRI, 1995).

Pensar um currículo como rizoma tendo como princípio a cartografia, implica pensar sob a perspectiva de acompanhar movimentos, indo nas linhas da invenção, da criação, não mais da representação. Assim, no movimento de desterritorialização e reterritorialização o currículo-rizoma vai se constituindo. Nesse sentido, o rizoma cria não reproduz, não se constitui como modelo a ser seguido. Um currículo rizoma permite inúmeras possibilidades. Experimentamos um currículo atravessado por saberes diversos advindos das experiências vivenciadas pelos estudantes. Contudo, não nos preocupamos em alcançar um resultado final, mas acompanhar o percurso, pelo meio, pelo desdobramento do pensamento, pela potência de sua continuação. Seus conhecimentos sobre a pesca artesanal do mapará, abriram espaço para se trabalhar, por exemplo, noções de habitat e nicho ecológico do peixe com os estudantes da EJA.

No cotidiano da sala de aula, no currículo, apesar do pensamento representativo, das linhas molares que são fixas e tentam aprisionar o currículo, há sempre outras linhas, as linhas moleculares que se movimentam e permitem passagem aos fluxos. O currículo de ciências então acontece no movimento, não a partir dos objetivos traçados pelo Ministério ou Secretarias de Educação, mas a partir da aula que potencializa possibilidades, criações. Isso nos leva a pensar que todo saber é potencial criador do devir e, que experimentar um currículo rizoma onde um possa aprender com o outro, onde os conhecimentos se conectem, se atravessem, em qualquer 
posição, tomar o currículo como mapa que permite receber modificações, perceber as linhas e os movimentos num currículo que está em permanente construção pode possibilitar fuga das prescrições, das visões reducionistas que tentam engessá-lo.

\section{Considerações finais}

Pensar um currículo como acontecimento, criação, como multiplicidades que emergem das diversas relações de forças da sala de aula, pode possibilitar pensar um ensino de ciências por suas potencialidades, forças criadoras, mais do que por suas estruturas fixas de programas e currículos.

Foi pelo desejo de vivenciar/experienciar um currículo de ciências com os estudantes e professor da EJA, por seus movimentos, mais do que por prescrições a serem seguidas que aventuramo-nos nessa pesquisa tomando-a como encontros que perpassam por incertezas, mas que indicam/insinuam potências criadoras.

As aulas realizadas com os estudantes, permitiram-nos pensar que um currículo de ciências traçado por linhas fixas, de ordem hierárquica e homogênea, que se constitui como eixo do processo de ensino e aprendizagem em ciências acaba por delimitar, demarcar fronteiras, com isso limita a presença dos saberes negando ou excluindo outros, julgando e/ou determinando que saber é mais importante. Esse limite implica negligenciar diferença, não valorizar saberes que os estudantes trazem e que fluem como potência no processo educacional.

Essas forças presentes no currículo fizeram-nos pensar que esse conhecimento se constitui na experiência e abre outras possibilidades para um currículo de ciências com os estudantes da EJA; que existem muitos currículos possíveis; que um currículo de ciências vivo está em movimento; que os professores e estudantes da EJA não são territórios delimitáveis, linhas estanques, mas por suas singularidades potencializam um currículo vivo no entre espaço, entre lugar do currículo escolar maior, este que tende de todas as formas enclausurar os vazamentos.

\section{Referências}

AMORIM, A. C. R. Os roteiros em ação: multiplicidade na produção de conhecimentos escolares. In: LOPES, Alice Casimiro, MACEDO, Elizabeth (Org.). Currículo de Ciências em debate. Campinas, SP: Papirus, 2004.

AMORIM, Antônio C. R. OLIVEIRA, Inês Barbosa (Org.). Sentidos de currículo: entre linhas teóricas, metodológicas e experiências investigativas. Campinas, SP: E/UNICAMP; ANPEd, 2006.

BERTICELLI, Ireno Antônio. Currículo: tendências e filosofia. In: COSTA, Marisa Vorraber. O currículo nos limiares do contemporâneo (Org.). DP\&A. Rio de Janeiro, 2005.

CHASSOT, Attico. Educação Consciência. Santa Cruz do Sul: EDUNISC, 2007.

CHAVES, Silvia Nogueira e BRITO, Maria dos Remédios de. (Orgs). Formação e docência: perspectivas da pesquisa narrativa e autobiográfica. Belém: CEJUP, 2011.

DELEUZE, Gilles; GUATTARI, Félix. Kafka: Por uma literatura menor. Rio de Janeiro: Imago, 1977.

. Mil Platôs: Capitalismo e Esquizofrenia, v.1. Rio de Janeiro: Editora 34, 1995. 
CARTOGRAFANDO SABERES: POR ENTRE TRAÇOS RIZOMÁTICOS NO CURRÍCULO DE CIÊNCIAS... (1969). Lógica do Sentido; São Paulo: Perspectiva; 4ª edição - 2ª reimpressão; 2009.

GALLO, Sílvio. Deleuze \& Educação. Belo Horizonte : Autêntica, 2003.

PARAÍSO, Marlucy Alves. Diferença no currículo. Cad. Pesqui., Ago 2010, vol.40, no.140, p. 587-604.

PARAISO, Marlucy Alves. Currículo, desejo e experiência. Educ. Real. [online]. 2009, vol.34, n.02, p. 277-293. ISSN 0100-3143.

PASSOS, E; KASTRUP, V.; ESCÓSSIA, L. Pistas do método da cartografia: pesquisaintervenção e produção de subjetividade. Porto Alegra: Sulina, 2009.

TADEU, Tomaz. A Filosofia de Deleuze e o Currículo. Goiânia, Faculdade de Artes Visuais, 2004. 